\title{
Home Range, Movements, and Habitat Utilization of Striped Skunk (Mephitis mephitis) in Scarborough, Ontario, Canada: Disease Management Implications
}

\author{
Rick Rosatte ${ }^{1,2}$, Paula Kelly ${ }^{3}$ and Mike Power ${ }^{4}$ \\ ${ }^{1}$ Ontario Ministry of Natural Resources, Wildlife Research and Development Section, Trent University, 2140 East Bank Drive, \\ Peterborough, Ontario K9J 7B8 Canada \\ ${ }^{2}$ Corresponding author (e-mail: rick.rosatte@ontario.ca; telephone 705-755-2280) \\ 385 Arbor Pine Drive, Ortonville, Michigan, 48462 USA \\ ${ }^{4} 8$ Tuch Drive, Keswick, Ontario L4P 3P1 Canada
}

Rosatte, Rick, Paula Kelly, and Mike Power. 2011. Home range, movements, and habitat utilization of Striped Skunk (Mephitis mephitis) in Scarborough, Ontario, Canada: disease management implications. Canadian Field-Naturalist 125(1): 27-33.

A total of 28 Striped Skunks (Mephitis mephitis) were fitted with radio-transmitters and their movements were monitored in Scarborough (Toronto), Ontario, in 1986 and 1987. Mean annual home range size for combined sex and age classes of Striped Skunks was $0.9 \mathrm{~km}^{2}(\mathrm{SD}=1.4)\left(\right.$ range $\left.=0.1-5.0 \mathrm{~km}^{2}\right)$. Home ranges were smaller during winter $\left(\bar{\chi}=0.04 \mathrm{~km}^{2}\right.$, $\mathrm{SD}=0.05)$ than during fall $\left(\bar{\chi}=0.67 \mathrm{~km}^{2}, \mathrm{SD}=1.09\right)(P=0.055)$ but not different from ranges during spring $\left(\bar{\chi}=0.25 \mathrm{~km}^{2}\right.$, $\mathrm{SD}=0.31)$ or summer $\left(\bar{\chi}=0.27 \mathrm{~km}^{2}, \mathrm{SD}=0.43\right)$. Nightly movements ranged between $0.1 \mathrm{~km}$ and $3.0 \mathrm{~km}$ and were greatest during October. Skunks were located more often in field habitats (56\% of observations) than in residential (23\%), field/ industrial $(10 \%)$, or industrial $(8 \%)$ habitats. Ecological data on Striped Skunks were used in the design of rabies control tactics for use in urban areas in Ontario, Canada.

Key Words: Striped Skunk, Mephitis mephitis, home range, movements, Scarborough, Toronto, Ontario.

Striped Skunks (Mephitis mephitis) have been a primary vector of rabies in rural habitats of Ontario since the 1960s (Johnston and Beauregard 1969; Rosatte 1988). The disease was also prevalent in Striped Skunks in large urban centres of Ontario, including metropolitan Toronto (Rosatte et al. 1992). In view of this, it was imperative that ecological data be collected on urban Striped Skunks to assist in the design of effective wildlife rabies control programs. A radio-telemetry study was initiated in Scarborough (Toronto), Ontario, during July 1986, to study the movements and ecology of Striped Skunks. Those data were used in the design of rabies control programs targeting urban areas of Ontario. This paper reports on our findings during that study in 1986 and 1987.

\section{Study Area}

The study area consisted of an urban complex of $60 \mathrm{~km}^{2}$ in Scarborough, Ontario, Canada, centred on $43^{\circ} 42^{\prime} \mathrm{N}, 79^{\circ} 26^{\prime} \mathrm{W}$ (the eastern part of metropolitan Toronto). The human population density at the time of the study (circa 1986) was estimated at approximately 4200 people $/ \mathrm{km}^{2}$. The landscape of the study area was a mosaic of habitat classes \{ see Rosatte (1986) and Rosatte et al. (1987) for a complete description and habitat maps $\}$. The urban complex was intersected by the Rouge River system \{ see Rosatte et al. (1992) for a map of river systems $\}$.

\section{Methods}

Between July and November 1986, 28 Striped Skunks were live-captured with Tomahawk \#105, 106, or 108 cage traps (Tomahawk, Wisconsin) baited with sardines, in a $60 \mathrm{~km}^{2}$ area of Scarborough, Ontario. Traps were covered with a sheet of plastic to prevent the researcher from being sprayed. Skunks were then immobilized with ketamine hydrochloride $(20-30 \mathrm{mg} /$ $\mathrm{kg}$ ) via hand-held syringe or using a drug-pole containing a syringe, needle, and plunger mechanism, were vaccinated with an intramuscular injection $(1 \mathrm{~mL})$ of Imrab inactivated rabies vaccine (Merial Inc., Athens, Georgia) and DPAL (disptemper, parvovirus, adenovirus, leptosporosis), were fitted with a VHF radiocollar or implantable transmitter (148-152 Mhz, Lotek Engineering, Newmarket, Ontario, or Holohil Systems, Woodlawn, Ontario), and were released at the point of capture. Some juvenile Striped Skunks were handled without drugs using a net or bag. Striped Skunks were classed as adult male, adult female, juvenile male, or juvenile female.

Of the 28 Striped Skunks, 10 were adults (6 males, 4 females); they were fitted with radio-collars. The remaining 18 Striped Skunks (10 juvenile females, 7 juvenile males, and 1 adult male) were captured (same area) and immobilized, and transmitters $(22.9 \mathrm{~g}, 7.5 \mathrm{~cm}$ long, $2 \mathrm{~cm}$ diameter) (Lotek, Newmarket, Ontario) were implanted in the peritoneal cavity, as detailed by Rosat- 
te and Kelly-Ward (1988). Five of the implants malfunctioned during the course of the study and were replaced by radio-collars.

Striped Skunks were located with Lotek SRX 400 receivers and Yagi antennae (Lotek Engineering, Newmarket, Ontario) from 25 July 1986 to 1 July 1987. Some Striped Skunks were monitored continually on some nights of each month during the study, while others were located just once per day. During nightly tracking, Striped Skunks were located every 15-60 minutes from dusk to dawn, the frequency of locations depending on how many animals were being monitored. Locations (called "fixes") were calculated by the intersection of two or three compass bearings from the observer to the Striped Skunk's location, which was plotted on topographical maps. Striped Skunks were also located during the day at their den sites, and in some cases active animals were observed and their locations noted. As the distance from the observer to the animals was small $(<100 \mathrm{~m})$, any errors associated with triangulation were negligible. The type of habitat in which the Striped Skunks were located was also recorded. Habitats were classed as field, industrial, groomed grass, forested park, commercial, or residential. On some occasions, skunks were located on the border of field and industrial habitats. If this occurred, the habitat was classed as field/industrial although it was impossible to calculate the percentage of the area that was deemed to be field/industrial.

Home ranges using a Minimum Convex Polygon estimator were calculated using Home Range Tools for ArcGIS ${ }^{\circledR}$ software (Rodgers et al. 2005). An estimate is provided for annual and seasonal ranges of Striped Skunks using the total number of locations. At least 30 fixes were required for annual range analysis and 15 fixes for seasonal range analysis. This was determined by examining the data to estimate when additional fixes did not affect home range size. Seasonal home ranges included spring (March-May), summer (June-August), fall (September-November), and winter (December-February). Dispersal was arbitrarily defined as a movement of $\geq 1 \mathrm{~km}$ from the natal or summer home range. To determine the potential for Striped Skunks to spread infectious diseases, the maximum distance across annual home ranges was calculated using a line measurement tool (display travel) in Home Range Tools, ArcMap version 9.2, an option in ArcGIS $^{\circledR}$. The cumulative distance travelled by Striped Skunks on a nightly basis was also calculated using the display travel function.

Data were analyzed using Statistica 6.0 software. A main effects ANOVA was used to determine whether there were differences in age (adults vs. juveniles) or sex (males vs. females) in annual and seasonal home range size, whether there were differences in the maximum distances across home ranges, and whether there were differences in habitat utilization (Zar 1999). A one-way ANOVA was used to examine individual sex

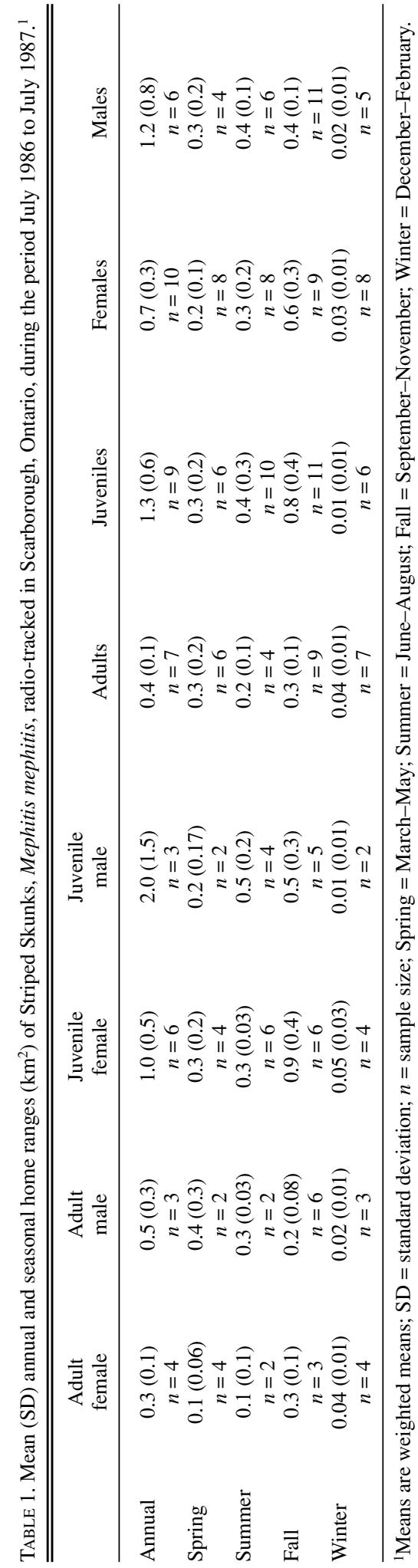




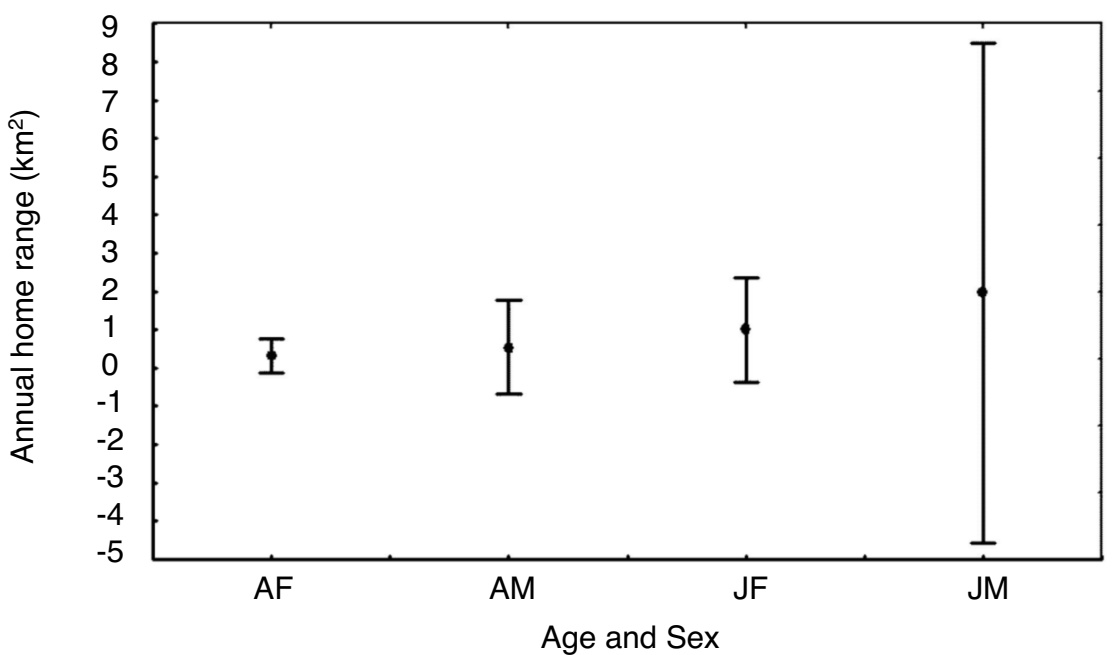

FIGURE 1. Mean annual home range size (95\% confidence interval) for 16 Striped Skunks, Mephitis mephitis, radio-tracked in Scarborough, Ontario, during the period July 1986 to July 1987 (AM = adult male; AF = adult female; JM = juvenile male; $\mathrm{JF}=$ juvenile female; mean $=$ weighted mean).

and age differences in home range size for each season as well as to detect differences in nightly movements of Striped Skunks on a monthly basis \{only for March to November, as Striped Skunks denned during the winter (December to February) \} (Zar 1999). As there were unequal numbers of home range values for different age and sex classes, the ANOVA calculated the weighted mean home range size (Zar 1999). If differences were found with the one-way ANOVA, a post hoc analysis was done using a Tukey test (Zar 1999). Since the data were not normally distributed (Zar 1999), a Friedman ANOVA comparing multiple variables by ranks was used to determine whether there were differences in habitat utilization (pooled data).

\section{Results}

Only partial data were supplied by 12 of the 28 Striped Skunks that were fitted with radio-collars or had transmitters implanted during 1986: 1 slipped its radio-collar, 6 died, and 5 of the radio-transmitters malfunctioned before the end of the study. Consequently, data from only 16 of the 28 animals (4 adult females, 3 adult males, six juvenile females, and 3 juvenile males) were used for annual home range and movement calculations. However, data from between 12 and 20 Striped Skunks were used for seasonal home range estimations, and data from all 28 Striped Skunks were used for habitat utilization calculations.

\section{Home range}

Area of annual home ranges: A total of 4624 locations were acquired during 1986 and 1987 on the 16 Striped Skunks that were used for annual home range analysis. The mean number of locational fixes per Striped Skunk was 289 (SD = 141.5). Annual home range size for juvenile Striped Skunks $\left(\bar{\chi}=1.3 \mathrm{~km}^{2}\right.$, $\mathrm{SD}=0.6 \mathrm{~km}^{2}$ ) was not significantly different from annual ranges for adult Striped Skunks $\left(\bar{\chi}=0.4 \mathrm{~km}^{2}\right.$, $\left.\mathrm{SD}=0.1 \mathrm{~km}^{2}\right)(F=2.02, P=0.18)$ (Table 1$)$ during the study. We could not detect any differences between the annual home range sizes of males and females ( $F=0.52, P=0.48$ ) (Table 1$)$. There were also no detectable differences in annual ranges among individual sex and age classes $(F=0.9, P=0.47)$ (Figure 1). Mean annual home range size for combined sex/age classes of Striped Skunks was $0.9 \mathrm{~km}^{2}(\mathrm{SD}=1.4$, range $=0.1-5.0 \mathrm{~km}^{2}$ ).

Area of seasonal home ranges: A total of 4968 locational fixes were used for seasonal home range analysis. The number of Striped Skunks per seasonal analysis ranged from 12 to 20 (Table 2). The mean number of locational fixes per Striped Skunk ranged from 47.6 to 111.6 (Table 2). No differences were detected in seasonal home range size based on age ( $F=1.33, P=0.37)$ or sex $(F=1.56, P=0.32)$ (Table $1)$. In addition, no differences in seasonal home range size were detected according to individual sex and age classes $(F=0.87, P=0.6)$ (Table 1$)$. When the data were pooled, there was a marginally insignificant difference in seasonal home range size $(F=2.54, P=0.066)$. Post hoc analysis indicated that home ranges were smaller during winter $\left(\bar{\chi}=0.04 \mathrm{~km}^{2}, \mathrm{SD}=0.05\right)$ than during fall $\left(\bar{\chi}=0.67 \mathrm{~km}^{2}, \mathrm{SD}=1.09\right)(P=0.055)$ but were not different from ranges during spring $(\bar{\chi}=0.25$ $\left.\mathrm{km}^{2}, \mathrm{SD}=0.31\right)$ or summer $\left(\bar{\chi}=0.27 \mathrm{~km}^{2}, \mathrm{SD}=0.43\right)$. 
TABLE 2. The number of locational fixes used during home range analyses of Striped Skunks, Mephitis mephitis, radiotracked in Scarborough, Ontario, during the period July 1986 to July 1987.

\begin{tabular}{lccc}
\hline \hline Season & $\begin{array}{c}\text { Number of Striped Skunks } \\
\text { used in the analysis }\end{array}$ & $\begin{array}{c}\text { Total number } \\
\text { of fixes }\end{array}$ & $\begin{array}{c}\text { Mean (SD) } \\
\text { number of fixes }\end{array}$ \\
\hline Annual & 16 & 4624 & $289(141.5)$ \\
Spring & 12 & 1008 & $99.0(84.5)$ \\
Summer & 14 & 667 & $47.6(27.6)$ \\
Fall & 20 & 2232 & $111.6(72.8)$ \\
Winter & 13 & 1061 & $81.6(25.5)$ \\
\hline \hline
\end{tabular}

${ }^{1} \mathrm{SD}=$ standard deviation

TABle 3. Mean nightly movements of 16 Striped Skunks, Mephitis mephitis, radio-tracked in Scarborough, Ontario, during the period July 1986 to July 1987 .

\begin{tabular}{lccccc}
\hline \hline Month & $\begin{array}{c}\text { Number of } \\
\text { tracking nights }\end{array}$ & $\begin{array}{c}\text { Mean number } \\
\text { of movements/ } \\
\text { night }(\mathrm{km})\end{array}$ & $\begin{array}{c}\text { Standard } \\
\text { deviation }\end{array}$ & $\begin{array}{c}\text { Minimum } \\
\text { distance travelled/ } \\
\text { night (km) }\end{array}$ & $\begin{array}{c}\text { Maximum } \\
\text { distance travelled/ } \\
\text { night (km) }\end{array}$ \\
\hline August 1986 & 10 & 0.5 & 0.3 & 0.2 & 0.9 \\
September 1986 & 25 & 0.8 & 0.6 & 0.1 & 2.5 \\
October 1986 & 34 & 0.9 & 0.6 & 0.3 & 3.0 \\
November 1986 & 28 & 0.3 & 0.3 & 0.1 & 2.1 \\
March 1987 & 19 & 0.2 & 0.2 & 0.1 & 0.6 \\
April 1987 & 7 & 0.4 & 0.2 & 0.1 & 0.7 \\
May 1987 & 21 & 0.7 & 0.6 & 0.1 & 1.8 \\
June 1987 & 8 & 0.9 & 0.3 & 0.5 & 1.4 \\
\hline \hline
\end{tabular}

${ }^{1}$ Although Striped Skunks were radio-tracked during the winter, movements were minimal (due to denning) and are not presented in this table. As the study began in late July 1986 and ended in early July 1987, no movement data were available for July.

Distance across home ranges: No differences in distances across ranges were noted based on age of the 16 Striped Skunks used in this analysis (adults vs. juveniles) $(F=2.45, P=0.14)$ or sex (males vs. females) $(F=0.83, P=0.38)$. Differences in distances across ranges were not found on an individual age/sex basis. Means distances across home ranges were as follows: adult females $0.9 \mathrm{~km}(\mathrm{SD}=0.2, n=4)$, adult males $1.4 \mathrm{~km}(\mathrm{SD}=0.3, n=4)$, juvenile females $1.7 \mathrm{~km}$ $(\mathrm{SD}=0.4, n=5)$, and juvenile males $2.0 \mathrm{~km}(\mathrm{SD}=1.0$, $n=3)(F=0.92, P=0.46)$ (Figure 2). Distances ranged from $0.7 \mathrm{~km}$ (home ranges of adult females) to $4.1 \mathrm{~km}$ (distances of juvenile males).

\section{Movements}

Nightly movements/month: A total of 16 different Striped Skunks (see Table 1 for age and sex) were tracked for a cumulative total of 152 nights between July 1986 and June 1987. As Striped Skunks denned during the winter from early December to early March and did not move any appreciable distance during that time, nightly movement data were analyzed on a comparative basis for the period August to November 1986 and the period March to June 1987 only (although Striped Skunks were radio-tracked during the intervening winter). As Striped Skunks were born in April, were not fully mobile until the summer, and denned during the winter, we compared nightly movements of juveniles and adults from August to November 1986 only.

We could not detect any differences in nightly movements of juveniles vs. adults from August to November $1986(F=0.084, P=0.98)$. When the data were pooled, a significant difference was detected in the cumulative distance travelled per night on a monthly basis $(F=6.40, P=0.0001)$. Post hoc testing revealed that nightly movement of Striped Skunks was significantly greater during September and October than during March and November (not including the winter months, December to February) $(P=0.0001)$ (Table 3 ). Nightly cumulative distance travelled ranged from a minimum of $0.1 \mathrm{~km}$ to a maximum of $3.0 \mathrm{~km} / \mathrm{night}$ (Table 3).

Winter movements: Striped Skunks generally did not move once they had entered their winter den. However, on eight occasions, Striped Skunks were documented moving $<0.1 \mathrm{~km}$ from the den during the period from 13 January to 9 February 1987. These movements were likely related to breeding activities. Movement $(<0.15 \mathrm{~km})$ was also noted on three occasions from 24 to 27 February 1987. This was related to Striped Skunks changing dens.

Dispersal: Of the 16 Striped Skunks that were used for annual home range analysis, only three were known 


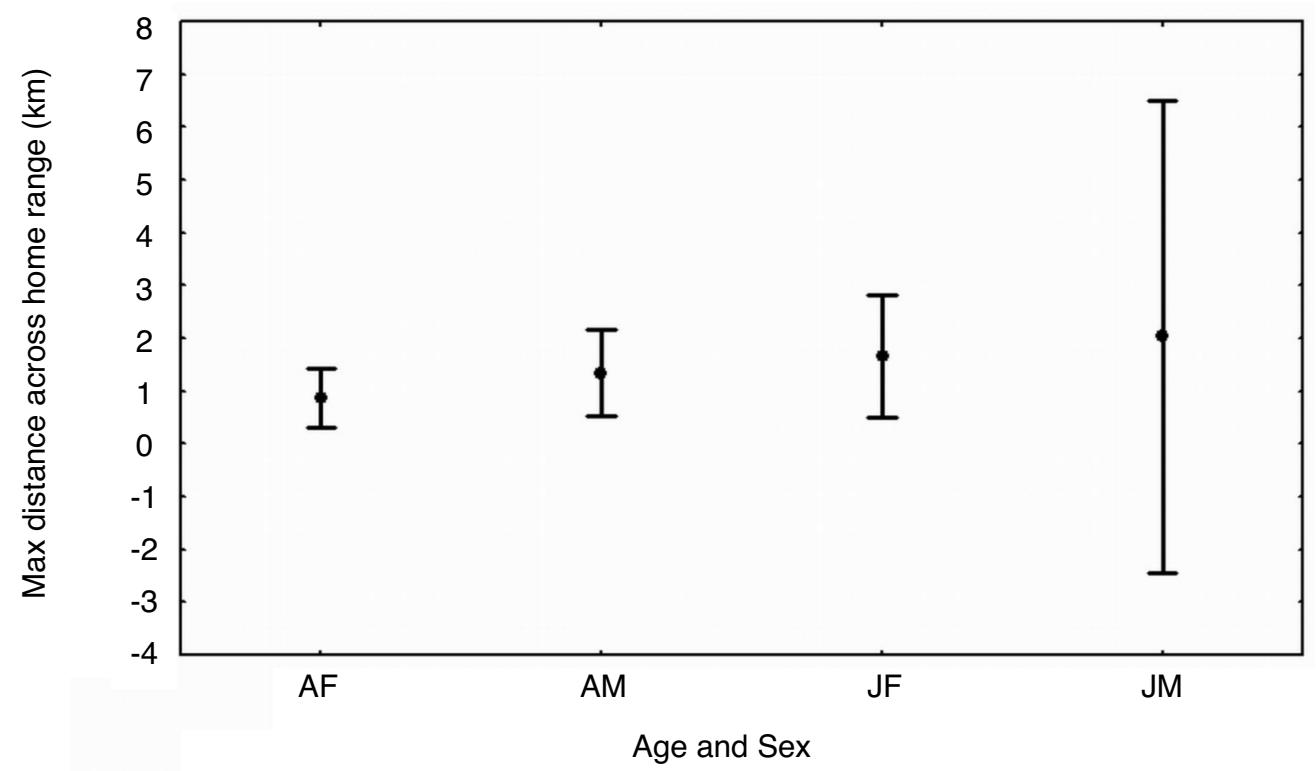

FIGURE 2. The mean (95\% confidence interval) of the maximum distance $(\mathrm{km})$ across the annual home range of 16 Striped Skunks, Mephitis mephitis, radio-tracked in Scarborough, Ontario, during the period July 1986 to July 1987 (AM = adult male; $\mathrm{AF}=$ adult female; $\mathrm{JM}=$ juvenile male; $\mathrm{JF}=$ juvenile female; mean = weighted mean).

to have dispersed greater than $1 \mathrm{~km}$ from their natal range during the study period-a juvenile female Striped Skunk dispersed $2.1 \mathrm{~km}$ on 19 September 1986, another juvenile female dispersed $1.1 \mathrm{~km}$ on $17 \mathrm{Sep}$ tember, and a juvenile male dispersed $3.1 \mathrm{~km}$ on 16 September.

Winter denning period: Data were available for 14 of the Striped Skunks during the entire winter denning period. Striped Skunks entered their winter dens between 4 and 11 December 1986 and left the dens in the spring between 4 and 15 March 1987. Eighty-six percent $(12 / 14)$ of winter dens were in ground burrows. The other dens were under a building and a shed.

Communal denning: During radio-tracking studies, Striped Skunks were noted as occupying winter dens with other Striped Skunks on eight occasions. On six of those occasions, two Striped Skunks (an adult female and an adult male; an adult female and a juvenile female; a juvenile female and a juvenile male; an adult female and an adult male; a juvenile female and an adult male; and two juvenile females) were found to be sharing a ground burrow den. On two occasions, three Striped Skunks were found to be in the same ground burrow den (an adult male, an adult female, and a juvenile female; and two adult females and a juvenile female).

Possible evidence of breeding activities: During our radio-tracking studies, we found evidence of
Striped Skunk movements that were probably related to breeding activities. On 13 January 1987, an adult male moved about $0.1 \mathrm{~km}$ to a den in a ground burrow. An adult female that had occupied a different ground burrow den with at least two other radio-collared females during December 1986 moved to the same ground burrow den on 13 January 1987. Another female, a juvenile, also moved to the same den in midJanuary. The three Striped Skunks shared the same den for two weeks, from 13 to 28 January 1987, until the adult male left the shared or communal den on 29 January and moved to another ground burrow about $100 \mathrm{~m}$ away. Both females moved back to their original ground burrow dens on 24 February.

\section{Habitat utilization}

Over the course of the study, the 28 Striped Skunks were located in specific habitats on 4973 occasions. The habitat composition of the study area included $57 \%$ residential, $17 \%$ industrial, $9 \%$ fields, $7 \%$ forested park, $6 \%$ groomed grass, and $4 \%$ commercial areas. Striped Skunks were located in field habitats during $56 \%$ of the observations (2795/4973) and in residential habitats during $23 \%(1162 / 4973)$ of the observations. Ten percent (496/4973) of skunk locations occurred on the border of fields and industrial habitats which were identified as field/industrial in terms of classification. Industrial habitats accounted for only $8 \%$ $(415 / 4973)$ of the observations. Locations in groomed grass, forested park, and commercial habitats ac- 
counted for a combined total of only $2 \%(105 / 4973)$ of the observations, so those data were deleted from the analysis.

We could not detect any differences in habitat utilization based on the sex and age of Striped Skunks $(F=1.318, P=0.29)$. When the data (all observations) were pooled, Striped Skunks were located in field habitats more frequently than in residential, field/ industrial, or industrial habitats (in that order) (ANOVA chi square $=30.2, P<0.0001)$. Fields accounted for only $9 \%$ of the study area.

\section{Mortality}

Six mortalities were confirmed during the study. Four were due to predation, most likely dogs, and two were due to infections likely associated with the implantable transmitters.

\section{Discussion}

Home range size and movements of Striped Skunks in this study were comparable to findings from studies in other urban areas, including Toronto (Rosatte et al. 1991), Niagara Falls (Rosatte et al. 2010), San Francisco (Boydston 2005), and Chicago (Gehrt 2004). This is likely due to the fact that urban habitats provide an ample supply of food and shelter in confined spaces, more so than in rural landscapes. In addition, Striped Skunks are by nature a fairly sedentary animal compared to other urban species, such as Coyotes (Canis latrans), Red Foxes (Vulpes vulpes), and Raccoons (Procyon lotor) (Gehrt and Riley 2010; Hadidian et al. 2010; Rosatte et al. 2010; Soulsbury et al. 2010).

Small home ranges and movements are an advantage when disease control strategies in urban environments are being planned. If an animal is less mobile, containment areas can be smaller and are less costly to implement, and the disease can be controlled much more quickly (Rosatte et al. 1997). However, as noted in this study, some juvenile Striped Skunks may disperse in mid- to late September. In view of this, rabies control strategies should be implemented prior to the period of dispersal to avoid juvenile Striped Skunks disseminating the disease.

Seasonal home ranges for Striped Skunks in this study were smallest during the winter months. This is due to the fact that Ontario has relatively severe winters that limit food availability for Striped Skunks in urban areas (Ontario Ministry of Natural Resources 1997). As a result, Striped Skunks den, often communally, from early December to early March in order to conserve energy. However, they may leave the winter den for mating in mid- to late January (Rosatte and Lariviere 2003). Communal denning by Striped Skunks, combined with the fact that Striped Skunks breed in communal dens (males being polygamous), contributes to the spread of diseases such as rabies (Rosatte and Lariviere 2003; Rosatte et al. 2007a). However, as Striped Skunks are in their dens during much of the winter in northern climates such as Ontario, control of diseases such as rabies is not feasible during that period of time (early December to early March).

Generally, Striped Skunks remained in winter dens, usually ground burrows, from early December to early March during this study. This is a wise strategy for Striped Skunks, as temperatures often dip below freezing during the winter and limit the availability of food (such as insects) in areas such as metropolitan Toronto (http://climate.weatheroffice.gc.ca/climateData/hourl ydata_e.html?timeframe $=1 \&$ Prov $=$ ON\&StationID =5097\&hlyRange=1953-01-01/2011-06-

$12 \&$ Year=1987\& Month=1\&Day=11). However, movements to other dens were noted in mid-January during this study. We assumed that movements of males and females to different dens during mid-winter was due to breeding activities, i.e., seeking mates. The temperature on 13 January 1987, when the male and female Striped Skunks moved to the same den, was $-1^{\circ} \mathrm{C}$ (http:// climate.weatheroffice.gc.ca/climateData/hourlydata_e.html?timeframe $=1 \&$ Prov $=\mathrm{ON} \& \mathrm{St}$ ationID=5097\&hlyRange =1953-01-01\%7C2011-06$12 \&$ Month $=1 \&$ Day $=13 \&$ Year $=1987 \& \mathrm{cmdB} 1=\mathrm{Go})$. From an energy conservation perspective, it does not make sense for a Striped Skunk to spend energy moving to another den when the temperature is cold unless the movement is associated with breeding.

Telemetry data in this study revealed extensive use of field and residential habitats by Striped Skunks. This is interesting, as fields accounted for only $9 \%$ of the study area. Rosatte et al. (1991) also found high use of fields by Striped Skunks during a live-trapping program in Toronto, Ontario. As Striped Skunks feed primarily on grubs and insects, such as beetles, grasshoppers, and crickets, it makes sense for Striped Skunks to spend much of their time foraging in field areas and residential yards and gardens (Rosatte and Lariviere 2003; Rosatte et al. 2010). Fields also provide areas where soils, vegetation, and drainage are conducive to the construction of ground burrows for denning. Residential yards also provide structures such as sheds, stairs, decks, and garages under which Striped Skunks may construct winter and maternal dens. Given the high use of fields and residential areas by Striped Skunks, rabies control tactics targeting Striped Skunks in urban areas should focus on those habitats (Rosatte et al. 1992, 1997, 2007a).

This study provided information on the ecology of Striped Skunks in urban areas in Ontario. The Ontario Ministry of Natural Resources (OMNR) used vector ecological data from this study, as well as others, to design effective tactics for the control of rabies in Ontario. As a result, the arctic variant of rabies was eliminated from metropolitan Toronto by 1996 (Rosatte et al. 1992, 2007b) and the raccoon variant of rabies was eliminated in eastern Ontario by 2005 (Rosatte et al. 2001, 2009). 


\section{Acknowledgements}

This research was supported by the Ontario Rabies Advisory Committee, the Wildlife Research Section of the Ontario Ministry of Natural Resources in Maple, Ontario, and the Wildlife Research and Development Section of the Ontario Ministry of Natural Resources in Peterborough, Ontario.

\section{Literature Cited}

Boydston, E. 2005. Behavior, ecology and detection survey of mammalian carnivores in the Presidio: Final Report. Western Ecological Research Center, U.S. Geological Survey, Sacramento, California. 80 pages.

Gehrt, S. 2004. Ecology and management of striped skunks, raccoons, and coyotes in urban landscapes. Pages 81-104 in Predators and People: From Conflict to Conservation, edited by N. Fascione, A. Delach, and M. Smith. Island Press, Washington, D.C.

Gehrt, S., and S. Riley. 2010. Coyotes (Canis latrans). Pages 79-95 in Urban Carnivores: Ecology, Conflict and Conservation, edited by S. Gehrt, S. Riley, and B. Cypher. Johns Hopkins University Press, Baltimore, Maryland.

Hadidian, J., S. Prange, R. Rosatte, S. Riley, and S. Gehrt. 2010. Raccoons (Procyon lotor). Pages 35-47 in Urban Carnivores: Ecology, Conflict and Conservation, edited by S. Gehrt, S. Riley, and B. Cypher. Johns Hopkins University Press, Baltimore.

Johnston, D. H., and M. Beauregard. 1969. Rabies epidemiology in Ontario. Bulletin of the Wildlife Disease Association 5: 357-370.

Ontario Ministry of Natural Resources. 1997. The snow network for Ontario wildlife. Ontario Ministry of Natural Resources, unpublished report, 18 pages.

Rodgers, A., A. Carr, L. Smith, and J. Kie. 2005. Home Range Tools for ArcGIS. Ontario Ministry of Natural Resources, Centre for Northern Forest Ecosystem Research, Thunder Bay, Ontario, Canada.

Rosatte, R. C. 1986. A strategy for urban rabies control: social change implications. Ph.D. dissertation, Walden University, Minneapolis, Minnesota. 311 pages.

Rosatte, R. C. 1988. Rabies in Canada: history, epidemiology and control. Canadian Veterinary Journal 29: 362-365.

Rosatte, R., and P. Kelly-Ward. 1988. A surgical procedure for implanting radio transmitters in Striped Skunks, Mephitis mephitis. Canadian Field-Naturalist 102: 713-715.

Rosatte, R., and S. Lariviere. 2003. Skunks (Genera Mephitis, Spilogale and Conepatus). Pages 692-707 in Wild Mammals of North America: Biology, Management and Conservation, edited by G. Feldhamer, B. Thompson, and J. Chapman. Johns Hopkins University Press, Baltimore, Maryland.

Rosatte, R., P. Kelly-Ward, and C. MacInnes. 1987. A strategy for controlling rabies in urban skunks and raccoons.
Pages 54-60 in Integrating Man and Nature in the Metropolitan Environment, edited by L. Adams and D. Leedy. National Institute for Urban Wildlife, Columbus, Maryland.

Rosatte, R., M. Power, and C. MacInnes. 1991. Ecology of urban skunks, raccoons and foxes in metropolitan Toronto. Pages 31-38 in Wildlife Conservation in Metropolitan Environments, edited by L. W. Adams and D. L. Leedy. National Institute for Urban Wildlife, Columbus, Maryland.

Rosatte, R., M. Power, C. MacInnes, and J. Campbell. 1992. Trap-vaccinate-release and oral vaccination for rabies control in urban skunks, raccoons and foxes. Journal of Wildlife Diseases 28: 562-571.

Rosatte, R., C. MacInnes, R. Taylor Williams, and O. Williams. 1997. A proactive prevention strategy for raccoon rabies in Ontario, Canada. Wildlife Society Bulletin 25: 110-116.

Rosatte, R., D. Donovan, M. Allan, L. Howes, A. Silver, K. Bennett, C. MacInnes, C. Davies, A. Wandeler, and B. Radford. 2001. Emergency response to raccoon rabies introduction into Ontario. Journal of Wildlife Diseases 37: 265-279.

Rosatte, R., R. Tinline, and D. Johnston. 2007a. Rabies control in wild carnivores. Pages 595-634 in Rabies, edited by A. Jackson and W. Wunner. Second edition. Academic Press, San Diego, California.

Rosatte, R. C., M. Power, D. Donovan, J. C. Davies, M. Allan, P. Bachmann, B. Stevenson, A. Wandeler, and F. Muldoon. 2007b. Elimination of arctic variant rabies in red foxes, metropolitan Toronto. Emerging Infectious Diseases 13: 25-27.

Rosatte, R., D. Donovan, J. C. Davies, M. Allan, L. Bruce, T. Buchanan, K. Sobey, B. Stevenson, M. Gibson, T. MacDonald, M. Whalen, F. Muldoon, and A. Wandeler. 2009. The control of raccoon rabies in Ontario, Canada: proactive and reactive tactics, 1994-2007. Journal of Wildlife Diseases 45: 772-784.

Rosatte, R., K. Sobey, J. Dragoo, and S. Gehrt. 2010. Striped skunks and allies (Mephitis spp.). Pages 97-106 in Urban Carnivores: Ecology, Conflict and Conservation, edited by S. Gehrt, S. Riley, and B. Cypher. Johns Hopkins University Press, Baltimore, Maryland.

Soulsbury, C., P. Baker, G. Iossa, and S. Harris. 2010. Red foxes (Vulpes vulpes). Pages 63-75 in Urban Carnivores: Ecology, Conflict and Conservation, edited by S. Gehrt, S. Riley and B. Cypher. Johns Hopkins University Press, Baltimore, Maryland.

Zar, J. 1999. Biostatistical Analysis. Prentice Hall, Upper Saddle River, New Jersey.

Received 13 October 2010

Accepted 6 April 2011 